\title{
Seismic and structural response of a framed four level building with RC and steel structure designed according to current Venezuelan codes
}

\author{
R. Ugel ${ }^{1}$, R. I. Herrera ${ }^{1}$, J. C. Vielma ${ }^{1}$, A. Barbat ${ }^{2} \&$ L. Pujades ${ }^{2}$ \\ ${ }^{I}$ Structural Engineering Department, School of Civil Engineering, \\ Lisandro Alvarado University, Barquisimeto, Venezuela \\ ${ }^{2}$ Senior Technical School of Roads, Canals and Ports Engineers of \\ Barcelona, Technical University of Catalonia, Barcelona, Spain
}

\begin{abstract}
This study determines the structural behavior of a four level framed building with composite RC and steel structure designed according Venezuelan seismic codes. The structural system consists of RC frames in the first three levels and steel frames in the fourth. It was performed linear analysis to design all structural elements. Capacity curves and performance points were obtained with pushover analysis. Results showed greater ductility in the $X$ frames' direction and greater resistance reserve in the external frames. Performing points showed adequate resistance values but low stiffness in two $Y$ frames' directions. Seismic action is carried on through synthetic accelerograms defined by the seismic codes used in this study. Dynamic analysis is used to compute parameters of ductility, over strength and displacements. In one case the collapse Limit State was reached, implying a general collapse of the building. Incremental dynamic analysis was performed to obtain fragility curves and damage probability matrix; a very high probability of significant lateral displacement and damage was evidenced from this despite a normative design of structural elements.
\end{abstract}

Keywords: composite structure, performance point, incremental dynamic analysis, fragility curves. 


\section{Introduction}

This study analyzes a model of residential building with 2 apartments per floor located in the metropolitan area Cabudare-Barquisimeto, Venezuela. It is a framed structure with four levels whose structural system consists of reinforced concrete in the first three levels and steel in the fourth. This vulnerability study is very important because this type of building currently is being widely used in different regions of the country. In the vulnerability assessment is necessary to determine the soil geophysical behavior on which the structure is located and the response of the building using for this purpose, design spectra characteristic of the area and computer simulations so it can be revealed the elastic and inelastic capacity curves of the structure, determining the building performance point, fragility curves and damage probability matrixes. Moreover, every structural design involves a rigorous analysis on the demands on the structure and consequently, the response of the building in terms of resistance, and seismic capacity should be carefully considered and evaluated. Thus, Chellini et al. [1] show that if the project involves two materials in the elements (Fig. 1) of the building structural system, it becomes very important that the assessment and response capacity of the building can be realized considering uncertainty, reliability and structural performance. Several studies have examined the design and analysis of these composite structures of steel and concrete and other researchers have focused on the seismic behavior of such structures. Papageorgiou and Gantes $[2,3]$ found that in the seismic project of this typology it can be found many unusual conditions, due to the inherent differences in the dynamic response of each structural material. They analyzed the complexities of different damping rates are irregular and different modes of vibration. Meanwhile, Li and Li [4] and Longo et al. [5] suggest that one of the key features of the advanced analysis and performance based seismic design is conducting a deep and detailed non-linear analysis of buildings in the inelastic range of material produced by high deformations caused by accidental excitations (earthquakes).

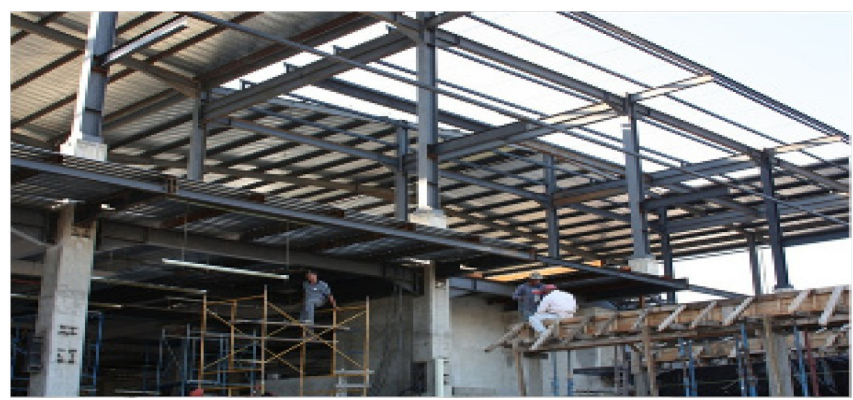

Figure 1: General view of primary and secondary structures. Barquisimeto.

In this context, Chen and Liu [6] studied hybrid RC and steel frames, revising effects as initial imperfections, cracking gradual effect and geometric and 
materials non linearity. Figure 2 shows a typical example of hybrid structure showing the combined use of steel (ductile) and RC (fragile) components. In general, it is established that the dominant effect on the elements of high slenderness is stability, but the material nonlinearity and the resulting nonlinearity in the stress-strain relationship in RC elements, can significantly affect the structural behavior.

a)
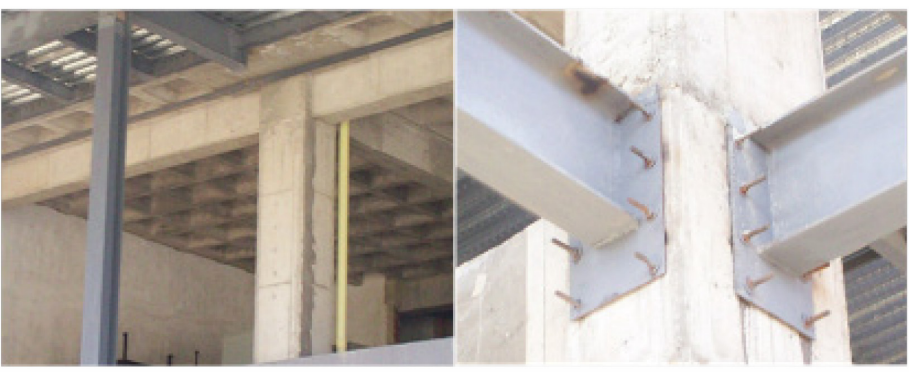

b)

c)
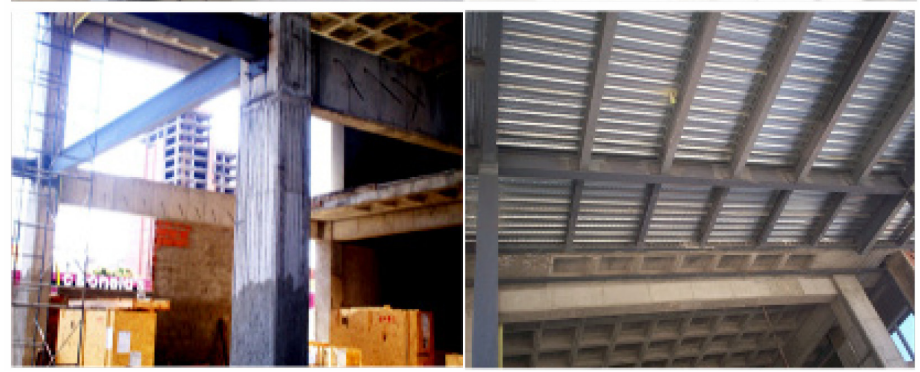

d)

Figure 2: $\quad$ a) Steel and RC typical plant joint; b) Beam-Column joint; c) Steel and RC beams and columns; d) Generic view of plant and primary and secondary beams. Barquisimeto, Venezuela.

Also, every structural component in composite structures are subject to the seismic action supported by the primary structure and rely on their own structural characteristics to resist such actions, as expressed by Chaudhuri and Gupta [8] and Medina et al. [9].

\section{Design of studied case}

The building has a framed structure with four levels in which the three lower levels have RC frames and the upper level have structural steel frames. Its use is residential and has two apartments per floor. The system has three resistant lines in the $Y$ direction and five resistant lines in the $X$ direction as shown in Figure 3. The building is designed according to Venezuelan COVENIN 1756:2001 [10]; COVENIN 1753:2006 [11] and COVENIN 1618:1988 [12] norms, not considering the effects of walls or internal partitions, so the level of performance will correspond only to the structural elements. 
a)

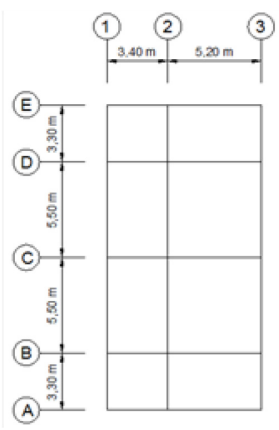

b)

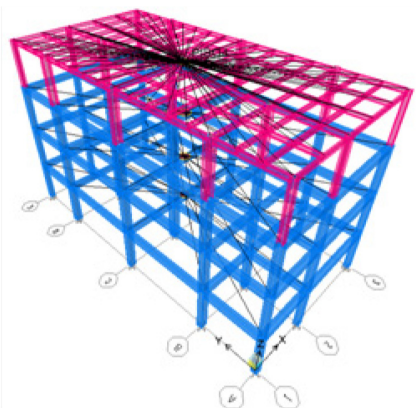

Figure 3: a) Plant dimensions; b) structure general view.

The building design was realized following the provisions of [10-12]; gravitational loads and actions were determined according COVENIN 2002-88 [13]. The seismic action was considered from the elastic spectrum corresponding to the emplacement site design of the building stiff soil according to [10].

\subsection{Inelastic analysis}

2D analysis was performed to all structure frames. Each one underwent two types of analysis: the static pushover analysis and dynamic time-history analysis. For the dynamic analysis the Ramberg-Osgood [14] steel model was used. In RC the constant nonlinear confinement was utilized (Figure 4); the confinement being determined by the Mander method [15].

a)

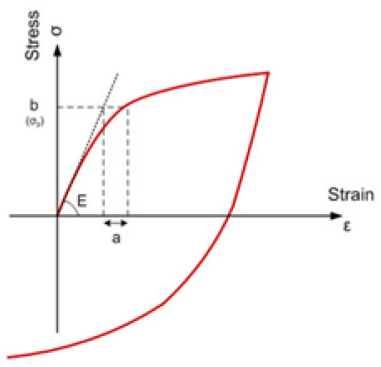

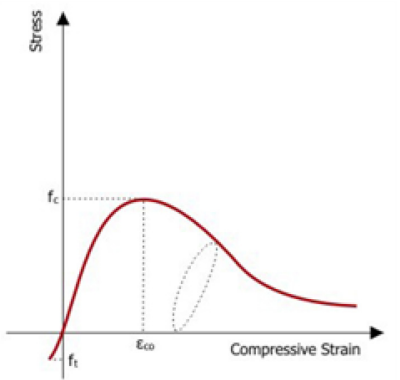

b)

Figure 4: a) Ramberg-Osgood steel constitutive model; b) concrete constitutive model with constant nonlinear confinement.

\subsection{Time-history dynamic analysis}

Frames were subjected to three types of earthquake for three different durations each one. These earthquakes were introduced through synthetic accelerograms generated with the program PACED (UCLA-CIMNE [16]), for each record. These records have been previously used by Ugel et al. [17]. The characteristics are shown in Table 1. 
Table 1: $\quad$ Utilized earthquakes description.

\begin{tabular}{c|c|c|c|c}
\hline Analysed earthquake & Limit State & $\begin{array}{c}\text { Return } \\
\text { period } \\
\text { (years) }\end{array}$ & $\begin{array}{c}\text { Duration } \\
\text { (seconds) }\end{array}$ & $\begin{array}{c}\text { Amplification } \\
\text { factor }\end{array}$ \\
\hline Frequent & Serviceability & 95 & 60 & 0.4 \\
\hline Rare & $\begin{array}{c}\text { Reparable } \\
\text { damage }\end{array}$ & 475 & 80 & 1.0 \\
\hline Very rare & $\begin{array}{c}\text { Prevention of } \\
\text { Collapse }\end{array}$ & 2475 & 100 & 2.0 \\
\hline
\end{tabular}

Incremental dynamic analysis (IDA), was applied to the frames' models (Vamvatisikos and Cornell [18]), following the method proposed by Chen and Lui [19]; this analysis was performed with unitary amplification for the three earthquake types.

\section{Results analysis}

The building fundamental period was obtained, which should be compared with the maximum stipulated by [9], which for this case was $0.6080 \mathrm{sec}$. It was determined a maximum value of $0.018 \%$ for lateral displacement for nonstructural elements susceptible to damage by deformation of the building. This verification was performed using the maximum value set by [10] and also was used the value proposed by Vielma et al. [20], in order to increase the stiffness requirement. The results showed that in all cases it was met as provided in the codes.

\subsection{Inelastic analysis}

Idealized capacity curves to each frame and ductility $(\mu)$, over strength $(\Omega)$ and the response reduction factor $(\mathrm{R})$ were obtained from static pushover analysis (Table 2).

Table 2: $\quad$ Ductility $(\mu)$, over strength $(\Omega)$ and response reduction factor $(\mathrm{R})$.

\begin{tabular}{c|c|c|c|c|c|c}
\cline { 2 - 7 } & Frame 1 & Frame 2 & Frame 3 & Frame A & Frame B & Frame C \\
\hline$\mu$ & 3.04 & 2.47 & 2.30 & 3.44 & 3.36 & 4.31 \\
\hline$\Omega$ & 3.05 & 2.07 & 3.29 & 2.21 & 1.98 & 1.98 \\
\hline $\mathrm{R}$ & 9.29 & 5.11 & 7.56 & 7.59 & 6.65 & 8.54 \\
\hline
\end{tabular}

Acceptable values of ductility from 2 to 5 and over strength greater than 1 for all frames were obtained; however, the response reduction factor $\mathrm{R}$ in frame 2 is lower than considered in design $(\mathrm{R}=6)$. The capacity curves are transformed to $\mathrm{Sa}-\mathrm{Sd}$ format to obtain capacity spectra, (Fajfar [21]) to each frame, following the methodology raised by Chiroui et al. [21] (Figure 5).

In superimposing the capacity spectra with the design spectrum in the same format, it was obtained the performance point of each frame, SEAOC [23]; from 
this procedure it is observed that frames have adequate lateral resistance, but frame 2 has insufficient stiffness by presenting very large lateral displacements.

a)

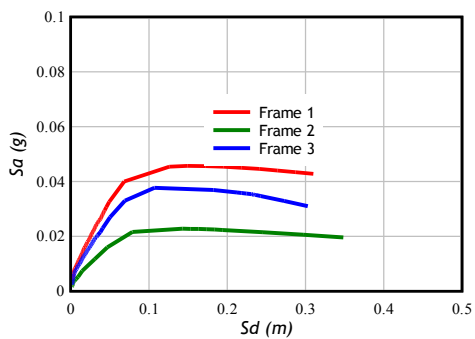

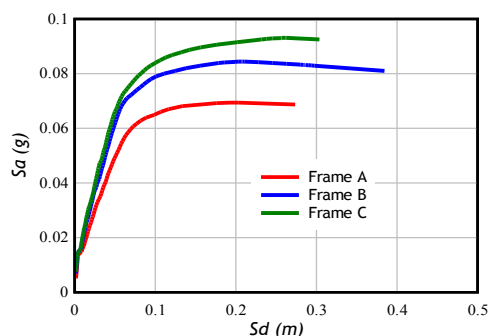

b)

Figure 5: $\quad$ Capacity spectra. a) Frames 1, 2 and 3; b) Frames A, B and C.

\subsection{Time-history dynamic analysis}

Global and inter story (local) drifts were graphed from each frame, some of which are shown below: (figures 6 to 9).

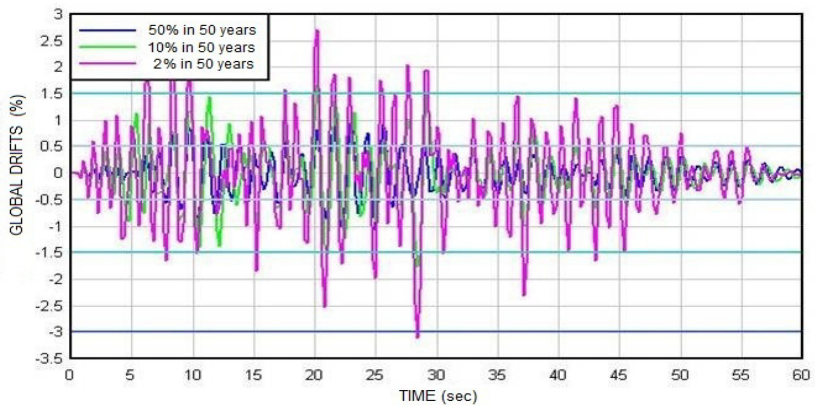

Figure 6: Global drifts. Frame 2 under $60 \mathrm{sec}$ earthquake.

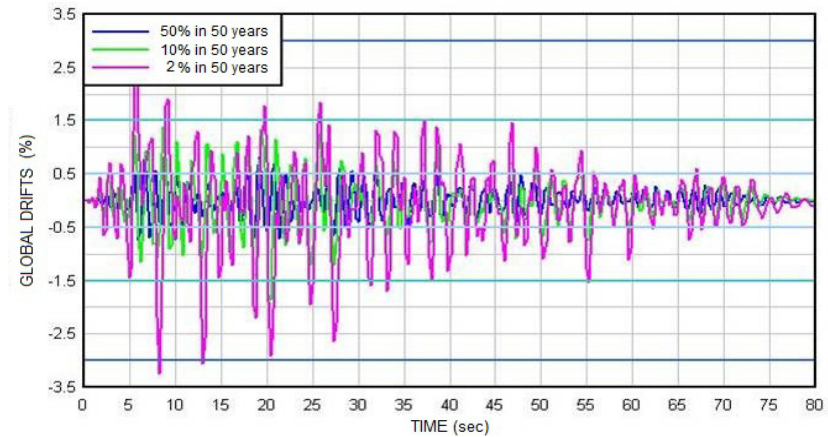

Figure 7: Global drifts. Frame 2 under $80 \mathrm{sec}$ earthquake. 


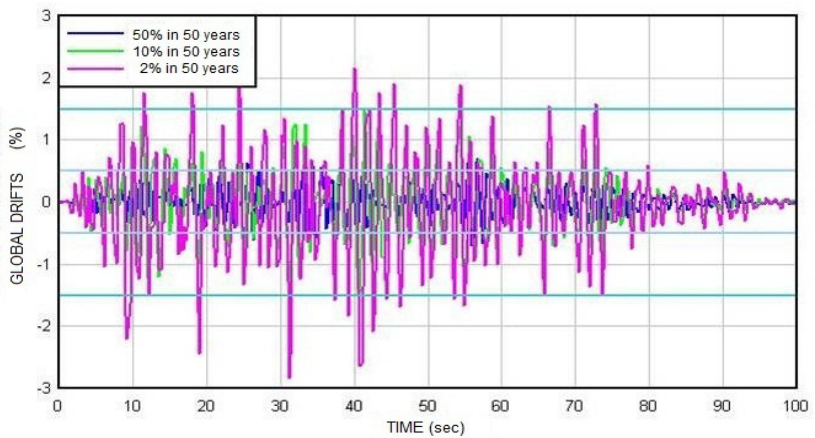

Figure 8: Global drifts. Frame 2 under $100 \mathrm{sec}$ earthquake.

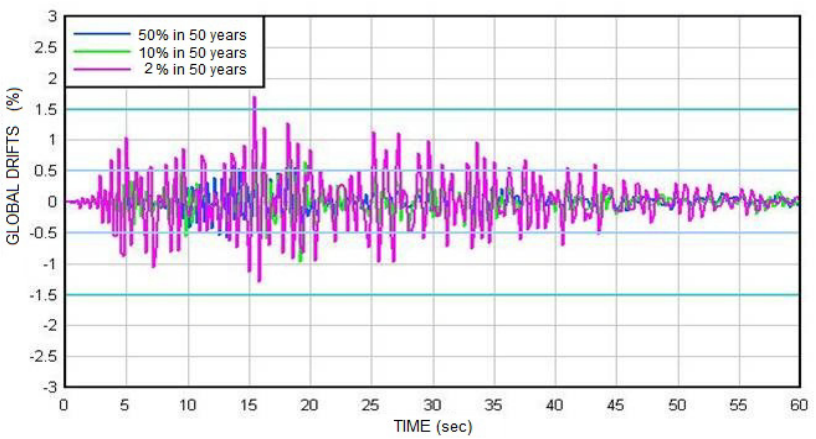

Figure 9: Global drifts. Frame B under $60 \mathrm{sec}$ earthquake.

In global drifts analysis, frame 2 exceeds the collapse prevention limit state in the very rare earthquake, while the more rigid frame is the $C$ frame which is not damaged in case of a frequent earthquake, sustain damage only in non-structural elements in case of a rare earthquake and reparable damage for a very rare earthquake (Figures 10-11).

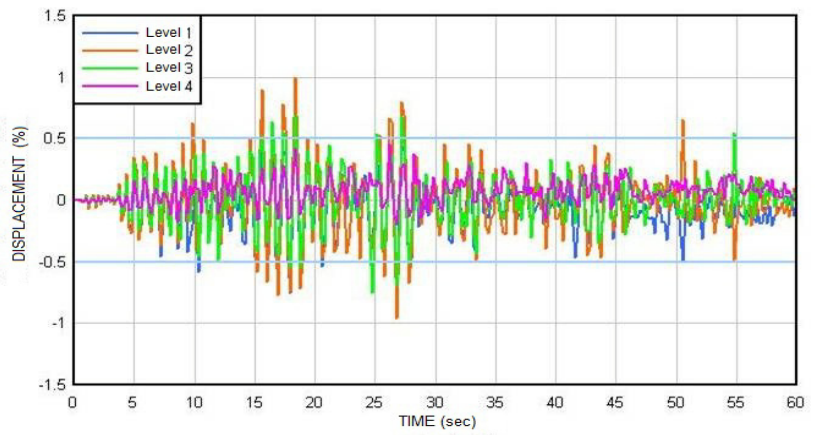

Figure 10: Local drifts, $60 \mathrm{sec}$. Frequent earthquake, Frame 1. 


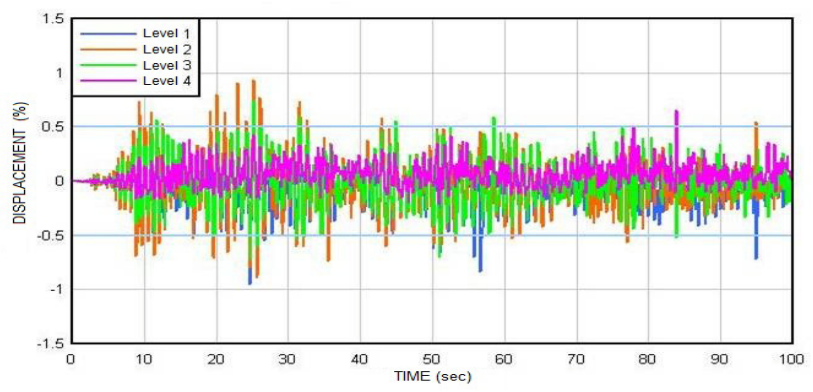

Figure 11: $\quad$ Local drifts, $100 \mathrm{sec}$. Frequent earthquake, Frame 1.

In inter story (local) drifts, levels with highest drifts under frequent earthquakes in direction $Y$ are levels 2 and 3, and on direction $X$ frames the higher drifts were generally at level 4 . For rare and very rare earthquakes, drifts are higher in level 2 for all frames. In very rare earthquakes, the prevention of collapse limit state was exceeded in almost all frames on at least one level, and was even exceeded this limit by frame 2 for a rare earthquake. Repairable damage limit state was exceeded by all frames for a rare earthquake and for frequent earthquake by frame 2. From Dynamic Pushover was obtained the acceleration vs. Drifts graphics for all frames. Figure 12 shows this graph for frame 2.

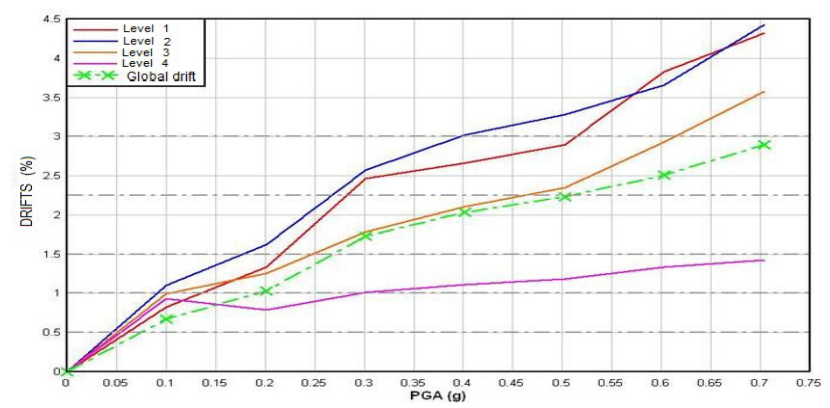

Figure 12: $\quad$ Frame 2, global and local drifts vs. acceleration.

From here, fragility curves in $X$ and $Y$ direction were built (Fig. 13). Using the design acceleration the damage probability matrix used by Pujades and Barbat [24] was obtained (as shown in table 3).

Table 3: $\quad$ Damage probability matrix. (\%).

\begin{tabular}{c|c|c|c|c|c}
\hline Direction & No damage & Slight & Moderate & Severe & Collapse \\
\hline$X$ & 0.66 & 7.91 & 34.01 & 43.37 & 14.05 \\
\hline$Y$ & 6.23 & 38.23 & 35.98 & 17.12 & 2.44 \\
\hline
\end{tabular}




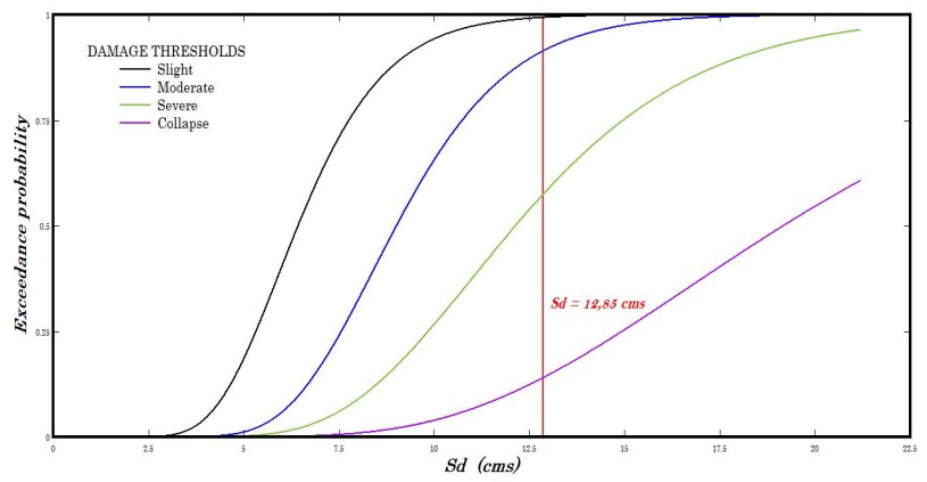

Figure 13: $\quad$ Fragility curve in $X$ direction.

The matrix results evidences that for the Limit States considered in this study, there is a significant difference in the seismic response when evaluating each resistant direction; while the $X$ direction shows a good chance of reaching the severe damage index, the $Y$ direction shows a greater propensity to reach the slight to moderate damage index, being these results proportional with the number of resistant lines in each direction.

\section{Conclusions}

It was determined that it's neither sufficient nor desirable to apply the elastic analysis design element by element, since excessive failures in non-structural elements generated by global or local excessive displacements can occur. In addition, the strong column-weak beam criteria could not be met, so there is no guarantee of a ductile response when the nonlinear range is reached. In nonlinear static analysis it was observed that capacity curves in $Y$ direction frames support higher lateral loads before the collapse than the $X$ direction frames, which is understandable considering the number of resistant lines in each direction. Over strength and ductility values that generally evidenced greater ductility in $Y$ direction frames were also obtained from this analysis and regarding the over strength values, it were higher for the external frames, being slightly higher in $Y$ directions frames; also, the obtained response reduction factor $\mathrm{R}$ was greater than the design value in all cases, excepted the 2 frame where this value is lower.

Studying the results of the performance point, all frames have adequate strength. However is very clear the inadequate stiffness in frame 2 as it has very large lateral displacements. Global drifts showed that the less rigid and therefore more susceptible to failure is frame 2 , since it even collapsed in very rare earthquakes, while the more rigid frame is $\mathrm{C}$ frame that would not suffer damage in frequent earthquakes and would sustain damage in non-structural elements only for a rare earthquake. According to these results all frames, excluding 2, have damage repairable damage in structural elements for very rare earthquakes 
and in general, for frequent and rare earthquakes, damage in non-structural elements. It should be noted that all beam-columns joints are rigid, so all the structure elements are susceptible to failure by overload under collapse of any frame, so despite having a structural design meeting all the regulations in codes, the structure collapses under a very rare earthquake.

Analyzing the local drifts is clear that information provided by global drifts is not sufficient, since in this case all frames exceeded the Limit State prevention of collapse for a very rare earthquake on at least 1 level, except for the $C$ frame, and is even exceeded in one case by the 2 frame for a rare earthquake which would imply the failure of the structure for this event. Here it becomes clear the importance of verify local drifts and not only the global ones, since low deformation on certain floors could compensate for excessive deformations in others, obtaining global values consistent with the normative but still reaching the collapse of the structure.

From fragility curves and damage probability matrix it is evident that under certain seismic and structural conditions, the building has a significant probability of severe or even collapse damage, despite being designed according to current seismic regulations.

It would be advisable to apply the same methodology used in this study to buildings with different combinations of number of floors, axis lengths, columns heights, levels of seismic hazard and numbers of RC and steel levels so it could be possible to compare with the typology studied, also considering irregularities in plants and elevation. It would improve much in this type of study and in seismic regulations, conducting investigations of buildings composed with other structural configurations, that way determining different dynamic behaviors, relative strength ratio and relative damping between the steel and $\mathrm{RC}$ elements.

\section{References}

[1] Chellini, G., De Roeck, G., Nardini, L. and Salvatore, W. (2010). Damage analysis of a steel-concrete composite frame by finite element model updating. Journal of Constructional Steel Research 66, 398-411.

[2] Papageorgiou, A. V. and Gantes, C. J. (2010). Equivalent modal damping ratios for concrete/steel mixed structures. Computers and Structures 88, 1124-1136.

[3] Papageorgiou, A. and Gantes, C. (2011). Equivalent uniform damping ratios for linear irregularly damped concrete/steel mixed structures. Soil Dynamics and Earthquake Engineering 31, 418-430.

[4] Li, G-G and Li, J-J. (2007). Advanced analysis and design of steel frames. $1^{\text {ra }}$ edición, London U.K. John Wiley and Sons Ltd. 368 p.

[5] Longo, A., Montuori, R. and Piluso, V. (2009). Seismic reliability of V-braced frames: Influence of design Methodologies. Earthquake engineering and structural dynamics. DOI: 10.1002/eqe.919.

[6] Chen, W. F. and Lui, E. M. (2006). Earthquake Engineering for Structural Design. CRC Taylor \& Francis Group, Boca Raton, Florida, USA. 
[7] Liu, S-W, Liu, Y-P and Chan, S-L. (2011). Advanced analysis of hybrid steel and concrete frames. Journal of Constructional Steel Research 2011, doi:10.1016/j.jcsr.2011.09.002.

[8] Chaudhuri, S. and Gupta, V. (2002). Variability in seismic response of secondary systems due to uncertain soil properties. Engineering Structures 24 (2002) 1601-1613.

[9] Medina, R, Sankaranarayanan, R. and Kingston, K. (2006). Floor response spectra for light components mounted on regular moment-resisting frame structures. Engineering Structures 28 (2006) 1927-1940.

[10] COVENIN 1756:01. (2001). Earthquake Resistant Design Code. Part 1, Caracas, Venezuela.

[11] COVENIN 1753:06 (2006). Design and construction of buildings with structural concrete. Caracas, Venezuela.

[12] COVENIN 1618:98 (1998). Steel structures for buildings. Limit States method. First review. Caracas, Venezuela.

[13] COVENIN 2002:88. (1988). Minimum actions and criteria for buildings design Code. Caracas, Venezuela.

[14] Ramberg, W. and Osgood, W.R. (1943). Description of stress-strain curves by three parameters. Technical Note No. 902, National Advisory Committee for Aeronautics, Washington DC. 1943.

[15] Mander, J. B., Priestley, M. J. N., and Park, R. (1988). Observed stressstrain behavior of confined concrete. Structural. Engineering, ASCE, 114(8), 1827-1849.

[16] UCLA-CIMNE. (2009). Compatible accelerograms with elastic design spectrum generation program. (PACED). International Center for Numerical Methods in Engineering. Lisandro Alvarado University, Venezuela.

[17] Ugel, R., Vielma, J. C., Herrera, R., Pérez, S. and Barbat, A. (2012). Seismic response of high rise steel framed buildings with chevron-braced designed according to Venezuelan codes. Natural Science, Earthquake Special Issue, August 2012, California, USA. Doi:10.4236/ns.2012.

[18] Vamvatisikos, D. and Cornell, C. (2002). Incremental dynamic analysis. Earthquake Engineering and Structural Dynamics 2002, 31:491-514.

[19] Chen, W. F. and Lui, E. M. (2006). Earthquake Engineering for Structural Design. CRC Taylor \& Francis Group. Boca Raton, Florida, USA.

[20] Vielma, J. C., Barbat, A. H. and Oller, S. (2010). Framed structures earthquake resistant project. International Center for Numerical Methods in Engineering Monograph. Earthquake Engineering Monographs, Barcelona, Spain.

[21] Fajfar, P. (1999). Capacity Spectrum method based on inelastic demand spectra. Earthquake Engineering and structural dynamics. Vol 28. pp. 979993.

[22] Chiroui, L., Goula, X., Roca, A., Susagna, T., Barbat, A. and Pujades, L. (2003). Capacity Spectrum Method applied to seismic damage assessment. 2nd Seismic Engineering National Congress, Málaga, España April 2003. 
120 Earthquake Resistant Engineering Structures IX

[23] SEAOC (1995). Vision 2000: Performance-based Seismic Engineering of Buildings, Structural Engineers Association of California, Sacramento California.

[24] Pujades, L and Barbat, A. (2008) Estimation of seismic vulnerability of most representative special importance buildings typology in Catalonia. IGC report. February. 2nd version. 